\title{
STUDIES ON ARIZONA ANTS (4) \\ CAMPONOTUS (COLOBOPSIS) PAPAGO, A NEW \\ SPECIES FROM SOUTHERN ARIZONA ${ }^{1}$
}

By WM. S. CreightoN

Department of Biology, College of the City of New York

This paper deals with ten colonies of Colobopsis taken by the writer in southern Arizona during the summers of 1950 and 1951. The work done during the second summer was made possible by a fellowship from the John Simon Guggenheim Memorial Foundation. Most of the observations on habits carried in this paper were made during the first months of a fifteen month survey of the ants of the southwestern United States and northern Mexico. I am happy to take this opportunity to express my sincere appreciation for this fellowship. I wish to thank Mr. Harry Stevens, the United States Agent in charge of the Papago Indian Reservation at Sells, Arizona, for his kindness in permitting us to use the Forestry Cabin on the western slope of the Baboquivari Mountains. We are also grateful to Mr. and Mrs. Forrest Perkins, who generously turned over their ranch house to us during our stay on the eastern slope of the Baboquivaris. The comfortable surroundings provided in each case greatly facilitated the work with the ants.

The older records for the species described in this paper were regarded by W. M. Wheeler as representatives of C. (Colobopsis) cerberulus Emery. For reasons which will be given later, I feel that it is a much sounder procedure to treat this ant as a new species. To do so involves the risk that it may subsequently prove to be cerberulus, as Wheeler supposed. But this risk must be taken if we are ever to get out of the fog which has obscured cerberulus from the time of its original recognition. In 1920 Emery described cerberulus from a single, winged female taken in the state

${ }^{1}$ Published with a grant from the Museum of Comparative Zoology at Harvard College. 
of Michoacan, Mexico (1). It is hard to understand why Emery felt that this specimen should be named. During the fifty years of entomological work which lay behind him, Emery had often struggled with the difficulties that result whenever a new species of ant is based on a dissociated female. Moreover, by 1920 the importance of accurate field data to an original description was clearly recognized. Yet Emery elected to describe an insect which wholly lacked significant field data. That the ant was known to have been taken in Michoacan is of scant significance, for that state has a singularly diverse topography and a corresponding diversity of biotic associations. Finally, Emery's description of cerberulus was brief and without figures. It was certain from the start that this description would be a source of trouble for, under the circumstances, nothing but a miracle could prevent subsequent confusion in the case of cerberulus.

Most of Emery's short description of cerberulus consists of a comparison of his unique type with the female of Wheeler's etiolatus. From the nature of this comparison it is evident that Emery had specimens of etiolatus at the time that he wrote the description of cerberulus. When Wheeler described etiolatus in 1904 (2) he presented no figure of the female and his description of that caste lacks certain features which Emery later cited. It is certain, therefore, that Emery had authentic material of etiolatus, probably from that part of the type series which Wheeler sent to Forel. It would otherwise have been impossible for Emery to have presented the characterization of the etiolatus female which he used in his comparison with the female of cerberulus.

The fact that this comparison utilized the female of etiolatus may well be what led Wheeler to believe that he could recognize the essential features which distinguish cerberulus; for Wheeler had type females of etiolatus in his own collection and with these as a guide he could secure a much more exact idea of the female of cerberulus than would be expected from Emery's brief account of that insect. It is now certain that Wheeler overestimated the utility of Emery's description. It is good enough to 
give a general idea of the female of cerberulus but it lacks the finer points which are necessary for the work that Wheeler attempted.

In 1920 Wheeler had in his collection a number of males and females of Colobopsis taken in southern Arizona. These specimens came from Texas Pass in the Dragoon Mountains, Sabino Basin in the Santa Catalina Mountains and Black Dike Prospect in the Sierrita Mountains. The specimens from Texas Pass had been taken by Wheeler at light. No field data accompanied the other specimens. Soon after Emery published his description of cerberulus, Wheeler identified the above specimens as that species. But no reference was made to them until 1934. In that year Wheeler published a paper (3) in which he attributed the Arizona material to cerberulus. He also described as cerberulus three major workers which Dr. Elizabeth Skwarra had collected near the city of Vera Cruz, Mexico. These specimens were taken in a hollow spine of Acacia sphaerocephala. Wheeler's association of the Arizona females with the Michoacan type was made on the basis of Emery's description. This could be defended, since the same caste was involved in each case. but the association of the Vera Cruz majors with cerberulus was a different matter. It was based on a comparison of the Vera Cruz majors with the Arizona females and on Wheeler's unsupported belief that the former represented the unknown major caste of cerberulus. I was forced to deal with this extraordinary double association when I was preparing the Colobopsis section of The Ants of North America (4). Since I could see no possibility of validating Wheeler's treatment of the Vera Cruz majors, cerberulus was omitted from the key. I commented on certain geographical discrepancies, which made Wheeler's association seem unlikely, but pointed out that there was little hope for bettering the matter until someone secured a nest of this ant in which both major worker and female were present.

It was, therefore, very gratifying to find such a colony in Garden Canyon, Huachuca Mountains, in July 1950. This colony was a fragment of a larger one, to judge from those subsequently taken, for it contained only eight in- 
dividuals. One of these was a deälated female, three were major workers and four were minor workers. The nest was found in a dead limb of Quercus emoryi. As soon as possible I took this nest to Harvard for comparison with material identified as cerberulus in the Wheeler Collection. This was put at my disposal through the courtesy of Dr. Joseph Bequaert whom I wish to thank for this kindness. The material labelled as cerberulus in the Wheeler Collection consisted of Skwarra's specimens from Vera Cruz and a series of females from Texas Pass in the Dragoon Mountains. To save possible confusion in the future it seems well to note that on the locality labels of these specimens the name is mispelled as the "Dragon Mountains". Texas Pass is a low pass at the western end of the Dragoon Mountains, through which the highway between Willcox and Benson now runs. The specimens from Sabino Basin and Black Dike Prospect, which Wheeler mentioned in 1934 could not be found. It is probable that these specimens are now in the collection of the American Museum of Natural History.

As I had expected, the female from Garden Canyon proved to be identical with those from Texas Pass. But the Garden Canyon majors were not the same as those from Vera Cruz. I have presented the differences in detail on a subsequent page. They need not be discussed here other than to state that, in my opinion, these differences clearly show that the two insects belong to separate species.

While the above comparison does not cover the second part of Wheeler's double association, it has given results significant to it. The head of the major of Colobopsis, like that of most species of ants in which this caste is present, differs more or less from that of its accompanying female. But there is no rule which governs the degree of difference. The amount of differentiation varies with the species and this circumstance defeats any attempt at anticipating the finer structure of one caste from that of the other. Since this is the case it should be obvious that nothing can be done with cerberulus until the unique female type can be proven identical with a female whose major worker is known. That this could be done by using Emery's 
description appears to the writer to be utterly impossible. Nor do I believe that a comparison of Emery's type with material now present in American collections would necessarily be conclusive. Since the Vera Cruz specimens are specifically different from those which occur in southern Arizona, there is good reason to suppose that the Michoacan type is also different. In all likelihood, therefore, a comparison of Emery's type with females taken in southern Arizona would merely substitute a new problem for an old one. For, unless the two proved identical, we would still have no idea as to the characteristics of the major of cerberulus. In all probability the nature of Emery's cerberulus will remain enigmatical until extensive collections of arboreal ants can be made in Vera Cruz and Michoacan. When complete colonies of Colobopsis can be taken in these states and compared with Emery's type the primary difficulty in the cerberulus problem may be overcome.

But we cannot wait until this is done to deal with a secondary difficulty which has resulted from Wheeler's unfortunate association. Since the Vera Cruz majors are specifically different from specimens coming from southern Arizona, the least that can be done is to provide a new name for one or the other of these insects, in order that the two species can be handled without violating nomenclatorial rules. I am convinced that it is best to treat the Arizona material as a new species for the following reasons:

(1). If only one new name is proposed the remaining species will have to be considered as cerberulus until this can be definitely authenticated or certainly disproved.

(2). From the standpoint of proximity it is much more likely that the Vera Cruz majors should be the same as the type of cerberulus. Southern Arizona lies seven hundred miles to the north of Vera Cruz and Michoacan. But the two states themselves are separated by less than two hundred miles and they lie in approximately the same latitudes.

(3). Any additional description in the case of the cerberulus complex should deal with adequate material about which there must be no occasion for speculative association. The Arizona material fully meets this condition. The Vera Cruz majors obviously do not. In connection 
with this last point it seems worth noting that in the ten colonies on which this study was based there were $23 \mathrm{fe}-$ males, 2 males, 104 major workers and 194 minor workers. These totals do not include 20 additional females taken at light.

There follows the description of the above material:

Camponotus (Colobopsis) papago sp. nov.

Major worker: head $1.06 \mathrm{~mm}$., thorax and petiole 1.5 $\mathrm{mm}$., overall length $4.5 \mathrm{~mm}$. (Plate 13, figure 3)

Truncated portion of the head distinctly concave, with a low, serrate flange bordering either cheek but not continued across the top of the clypeus. The entire clypeus raised slightly above the level of the adjacent portions of the cheeks, which slope downward to the clypeus from the bordering flange. Sculpture of the truncated portion of the head consisting of coarse, irregular ridges which form reticulations. These reticulations and the areas which they surround, are covered with numerous, very fine, crater-like punctures. These punctures do not dull the shining surface. Sculpture on the mandibles rough but not distinctly reticulate. Seen from above the frontal lobes are covered with even reticulations which surround circular or nearly circular depressions. This reticulate sculpture extends almost to the level of the single median ocellus, with the depressions becoming shallower and more widely spaced towards the rear. The rear third of the head is finely shagreened and notably more shining, particularly at the occipital corners, than is the heavily sculptured front of the head. The reticulation on that part of the clypeus which lies behind the truncation is much less even than that on the frontal lobes. Reticulation on the cheeks less even and somewhat coarser than that on the frontal lobes. The entire anterior half of the head with the same fine, crater-like punctures which occur on the truncated portion. A very feeble frontal furrow is visible in certain lights. Antennal scapes rather strongly shining with small, white, appressed hairs. Hairs on the truncated portion of the clypeus and on the front face of the mandibles very strongly clubbed and shaped like tear drops. Hairs along the outer border of the mandibles, on the 
frontal lobes and on the sides of the head behind the truncation long, curved, blunt and often clavate but rarely as strongly clubbed as those of the clypeus.

Thorax, petiole and gaster more finely shagreened than the head with the surface strongly shining. In addition to the shagreening there are very small scattered punctures present, from which arise short, delicate, fully appressed hairs. No erect hairs present on the thorax, those on the crest of the petiole very short and fine. Erect hairs rather sparse on the gaster, mainly confined to the row at the posterior edge of each segment. Legs finely shagreened and strongly shining with delicate, appressed hairs like those of the thorax. Fore femora expanded dorso-ventrally and strongly compressed laterally. The tarsal joints and the funiculi covered with abundant, short, yellowish, semierect hairs. Color deep blackish brown, the anterior third of the head clear yellowish brown. Tarsi, funiculi, base of the petiole and the sutures of the thorax light brown.

Worker minor: head $0.9 \mathrm{~mm}$., thorax and petiole 1.25 $\mathrm{mm}$., overall length $3.25 \mathrm{~mm}$. (Plate 13, figure 2)

Head, seen from the front, with the eyes notably more convex than those of the major, the sides in front of the eyes narrowing to the insertion of the mandibles. Mandibles with four well-developed teeth. Clypeus moderately convex from side to side, somewhat more strongly convex from front to rear, ecarinate or with a very blunt and indistinct carina. Frontal lobes together forming a trapezoidal area which is a little wider behind than in front. Frontal groove absent. Occiput evenly convex, the lateral portions meeting the posterior border of the eyes without any distinct posterior angles. The antennal scape, when extended straight to the rear, surpasses the occipital border by an amount slightly less than its greatest thickness. Head, thorax and abdomen moderately shining with a rather strong, reticulate shagreening. Appressed hairs as in the major and female. Erect hairs long, tapered and with sharp tips. They are rather numerous on the man-

Explanation of Plate 13

Camponotus (Colobopsis) papago. Fig. 1. Female. Fig. 2. Minor worker. Fig. 3. Major worker. (All figures drawn to same scale.) 

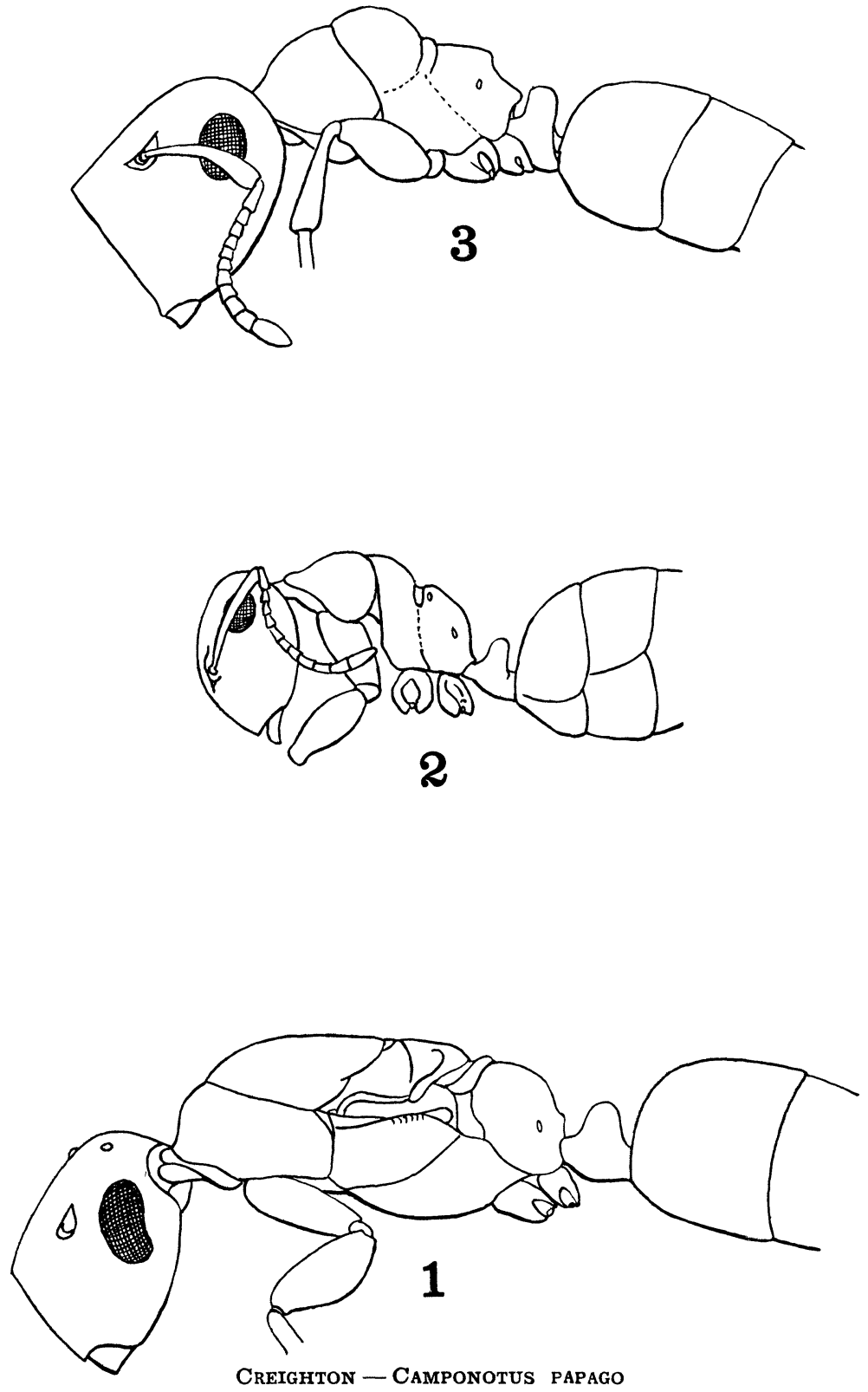
dibles and clypeus, sparser on the front and represented on the occiput by a single pair. Thorax without erect hairs. Crest of the petiole with several very short, delicate erect hairs. Erect hairs on the gaster widely and rather evenly spaced over the dorsum except at the base of the first segment, which is hairless. Fore femora laterally compressed as in the major. Color: blackish brown, the mandibles and tarsal joints light brown.

Female: head $1.25 \mathrm{~mm}$., thorax and petiole $2.3 \mathrm{~mm}$., overall length $6.0 \mathrm{~mm}$. (Plate 13, figure 1)

Head similar to that of the major but with all three ocelli large and prominent. Sculpture on the truncated

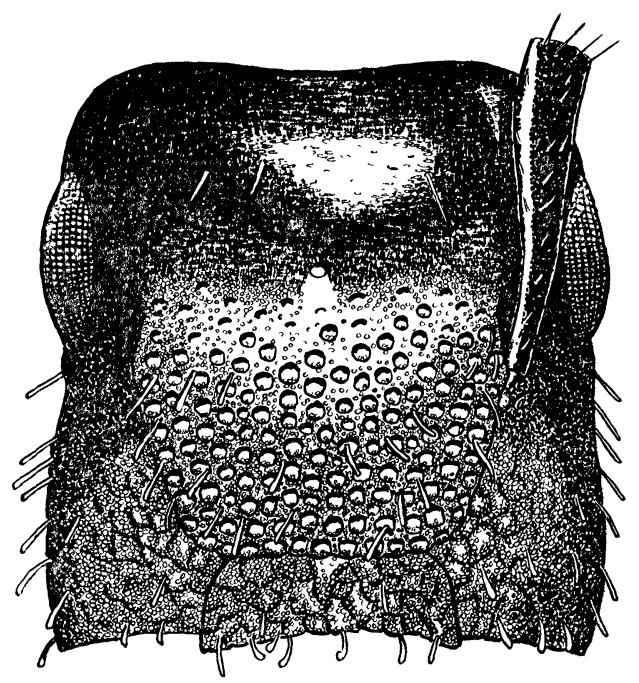

Text-figure 1. Upper sulface of the head of the major worker of Camponctus (Colobopsis) papago sp. nov.

portion of the head identical with that of the major. Reticulate sculpture on the frontal lobes smaller and shallower than that of the major and not extending as far back on the head. Eyes distinctly larger and more convex than those of the major. Hairs on the mandibles and the truncated portion of the clypeus longer and less clubbed than those of the major. 
Thorax feebly shagreened and rather strongly shining, with small, scattered, appressed hairs as in the major. Erect hairs absent on the thorax except for a pair of long, yellowish hairs which arise from the scutellum. Gaster more feebly shagreened and more strongly shining than the thorax but with similar appressed hairs. Erect hairs on the gaster only moderately abundant, mostly confined to a row at the rear of each segment. Erect hairs on the terminal gastric segment distinctly longer than those elsewhere. Fore femora laterally compressed as in the major. Color blackish brown, the anterior quarter of the head, much of the scutum and the middle and hind tarsi yellow-

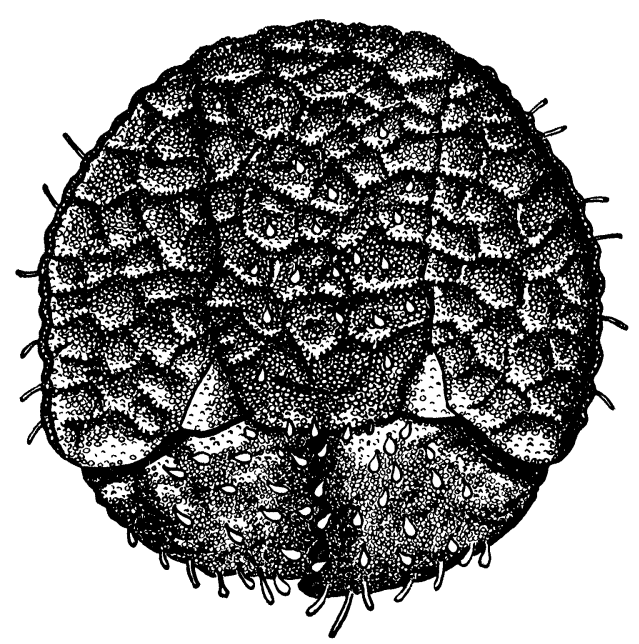

Text-figure 2. Truncated surface of head of major worker of Camponotus (Colobopsis) papago sp. nov.

ish brown. Wings hyaline, iridescent and with pale yellowish veins.

Male: Head $0.7 \mathrm{~mm}$., thorax $1.5 \mathrm{~mm}$., overall length $3.5 \mathrm{~mm}$.

The sides of the head in front of the eyes taper slightly from the anterior edge of the eye to the insertion of the mandible. Behind the eyes the sides of the head are evenly 
convex from the rear edge of the eye to the lateral ocellus. The occipital border is slightly concave between the lateral ocelli. Anterior border of the clypeus feebly sinuate. Mandibles small, somewhat spatulate and with the teeth represented only by a V-shaped notch on the masticatory margin. Antennal scapes long, surpassing the occipital margin by a little more than one-third their length.

The greatest width of the thorax, when seen from above is approximately equal to that of the head. In profile the neck of the pronotum is short, the anterior face of the scutum is evenly rounded and its dorsal face is flat and on the same level as the anterior edge of the scutellum. The latter is convex in profile and descends sharply in the rear. In profile the epinotum is depressed well below the level of the scutellum, rounded and without a good separation between the basal and declivious faces. Petiole with a short but distinct anterior peduncle, the node low in profile, tapering slightly from base to crest with the latter evenly rounded. Seen from above the node of the petiole is transversely oval, with the width about twice the thickness from front to back. Gaster approximately as long as the thorax. Genitalia small and obscure.

The surface is moderately to strongly shining. Front and genae strongly shining with scattered punctures. Occiput and scutum less shining with a delicate reticulate sculpture. Scutellum very shining with scarcely any sculpture. The remainder of the thorax and the node of the petiole with a reticulate sculpture which is less pronounced than that of the scutum. Gastric sculpture very feeble, shagreened but scarcely reticulate, the surface more shining than that of most of the thorax. Sparse erect hairs are present on the head, the coxae and the gaster. Thorax without erect hairs. Antennal scapes, the femora and the tibiae with very delicate, short, sparse hairs which are fully appressed. Pubescence on the antennal funiculi and the tarsal joints suberect and not particularly prominent. Thorax and gaster dirty, yellowish brown, the head distinctly darker. Wings hyaline and iridescent with the veins very pale.

Types of female, male, major and minor worker deposited 
in the Museum of Comparative Zoology, Cambridge, Mass. The type locality is Forestry Cabin (Baboquivari Canyon), Baboquivari Mts. $\left(3500^{\prime}\right)$, Arizona. The type nest was taken on July 24, 1951 in Quercus emoryi. Four other colonies were taken in this same station. In addition four more colonies were secured near Perkins Ranch in Brown Canyon on the eastern slope of the Baboquivari Mountains. These last colonies were situated at elevations between 4100 and 4600 feet. Mention has already been made of the single colony taken in Garden Canyon in the Huachuca Mountains. The elevation of the station from which this colony came was 5800 feet. $^{1}$

In the following paragraphs are given the results of the comparison between the major workers of papago and the three major workers from Vera Cruz which may be cerberulus :

1. In papago the length of the head is shorter in proportion to its width and the sides of the head in front of the eyes are slightly convex when the head is viewed from above. In the Vera Cruz majors the sides of the head in front of the eyes are straight or nearly so when the head is viewed from above.

2. In papago the scape only slightly surpasses the occipital margin. The amount of the scape which projects beyond the margin is notably less than the greatest diameter of the scape. In the Vera Cruz majors the scape surpasses the occipital margin by an amount equal to the greatest diameter of the scape.

3. In papago the triangular lateral portion of the mandible is feebly and irregularly concave on its anterior face. In the Vera Cruz majors the triangular, lateral portion of the mandible is so strongly concave on its anterior face that the tip of the triangle appears to point forward.

4. In papago the truncated portion of the clypeus is uniformly covered with coarse, reticulate ridges. In the Vera Cruz majors this portion of the clypeus is also reticu-

${ }^{1}$ Since the above was written nests of $C$. papago have been taken by the writer in Cottonwood Canyon, Peloncillo Mts. (4800'), Arizona and fourteen miles north of Imuris, Sonora $\left(3200^{\prime}\right)$, Mexico. In both cases the ants were nesting in $Q$. emoryi. 
late but at the middle of the clypeus there is a heavy, median ridge which runs from front to back. This ridge is wavy but it is not reticulate.

5. In papago the portion of the clypeus behind the truncation is not clearly set off from the frontal lobes and the frontal area is indistinct. In the Vera Cruz majors the portion of the clypeus behind the truncation is clearly separated from the frontal lobes and the frontal area, although small, is very distinct.

6. In papago the serrate flange at the edge of the truncated portion of the head is lower and less prominent than that of the Vera Cruz majors.

7. In papago the erect hairs on the sides of the head are longer, more numerous and less clavate than those of the Vera Cruz majors. In both species most of the hairs on the mandibles and the truncated portion of the clypeus are so strongly clubbed that they are shaped like tear drops. It is strange that Wheeler made no mention of these conspicuous and characteristic hairs. From a practical point of view they furnish the easiest means for distinguishing paprgo from any other species which occurs in the United States. None of our other species have such hairs, hence there is no possibility of confusing papago with any other species if these hairs are made the basis for its recognition.

Before concluding this paper I wish to present an account of the habits of $C$. papago. The ten colonies taken to date have all come from evergreen oaks or mesquite trees. The two oaks involved are Quercus emoryi and Q. oblongifolia. Most nests are constructed in the stubs of brokenoff branches which have a diameter of an inch and a half or more. The thickness of the stub seems to be more important than its length. I have taken colonies from stubs less than six inches long but I have yet to see one in a branch that was small enough to be considered a twig. Inside the stub are numerous, narrow passages which roughly parallel the grain of the wood. Several openings lead from these to the outside. It is evident that in a fully developed nest of papago there must be several "janitors" on duty at the same time. As mentioned above, this ant does not ordinarily nest in twigs. At first I supposed that 
this reaction might be due to a scarcity of trees which have twigs with a suitable central pith cavity and this may be a part of the explanation. But it now seems certain that moisture plays a large part in the choice of nest site. I had realized that papago usually nests in limb stubs which point upward long before I saw any significance in this response. But on one occasion I was examining limb stubs immediately after a heavy and prolonged rain storm. I found that the stubs which pointed upward caught and held the rain water much as a cistern would. Rain soaked into the fractured upper end of the stub and accumulated at its lower end. The lower end was often so wet that water would drip out of it after the stub was knocked loose from the tree. In contrast, the horizontal stubs and those which pointed downward caught far less rain. The latter were often quite dry inside, despite the fact that they had been drenched with rain for several hours previously. It thus appears that the female of papago, in choosing a nest site in limb stubs which point upward, takes advantage of a natural system of water conservation. This could certainly be one reason why the nesting habits of papago differ from those of the eastern twig-dwelling species. It may be added that the preference of this ant for nesting in the stubs of broken-off limbs seems to be one factor which has kept it out of the hands of collectors. It was some time before I realized that the most important piece of equipment needed to collect $C$. papago is a heavy axe. The nests are almost always built in sound, hard wood and it is not easy to get the insects out, even after the stub has been knocked loose. The ants which are in the lower passages can often be jarred out by whacking the stub with the back of the axe. But to get all of them the stub must be split into pencilsized pieces. Anyone who makes a practice of collecting papago will never lack for exercise.

The majors of $C$. papago, when disturbed, have a curious habit of exuding from the mouth a sticky, greyish fluid. This often spreads backward over the truncated portion of the head. If it is allowed to dry there it forms a crust that is almost impossible to remove. As to what the use of this fluid may be is hard to say. It may have repellant 
characteristics for other ants and thus serve as a defensive mechanism which the major employs when acting as a janitor at the nest entrance.

It is safe to infer that C. papago forages at night. Although I have examined hundreds of oak and mesquite limbs, some of which later proved to contain flourishing colonies of papago, I have never seen a worker outside the nest. This foraging must be a slow business, for papago is a rather sluggish ant. The minor workers can move with fair speed but the majors are so slow that it is easy to pick them up. Finally, the marriage flight of papago occurs throughout the month of July. In an ordinary year it would thus take place during the first half of the summer rainy season.

\section{Literature Cited}

1. Emery, Carlo

Bull. Soc. Ent. Ital., Vol. 52, p. 34, 1920.

2. WHEELER, W. M.

Bull. Amer. Mus. Nat. Hist., Vol. 20, p. 150, 1904.

3. WHEELER, W. M.

Bull. Mus. Comp. Zool., Vol. 77, No. 5, p. 214, 1934.

4. Creighton, W. S.

Ibid., Vol. 104, p. 392, 1950. 

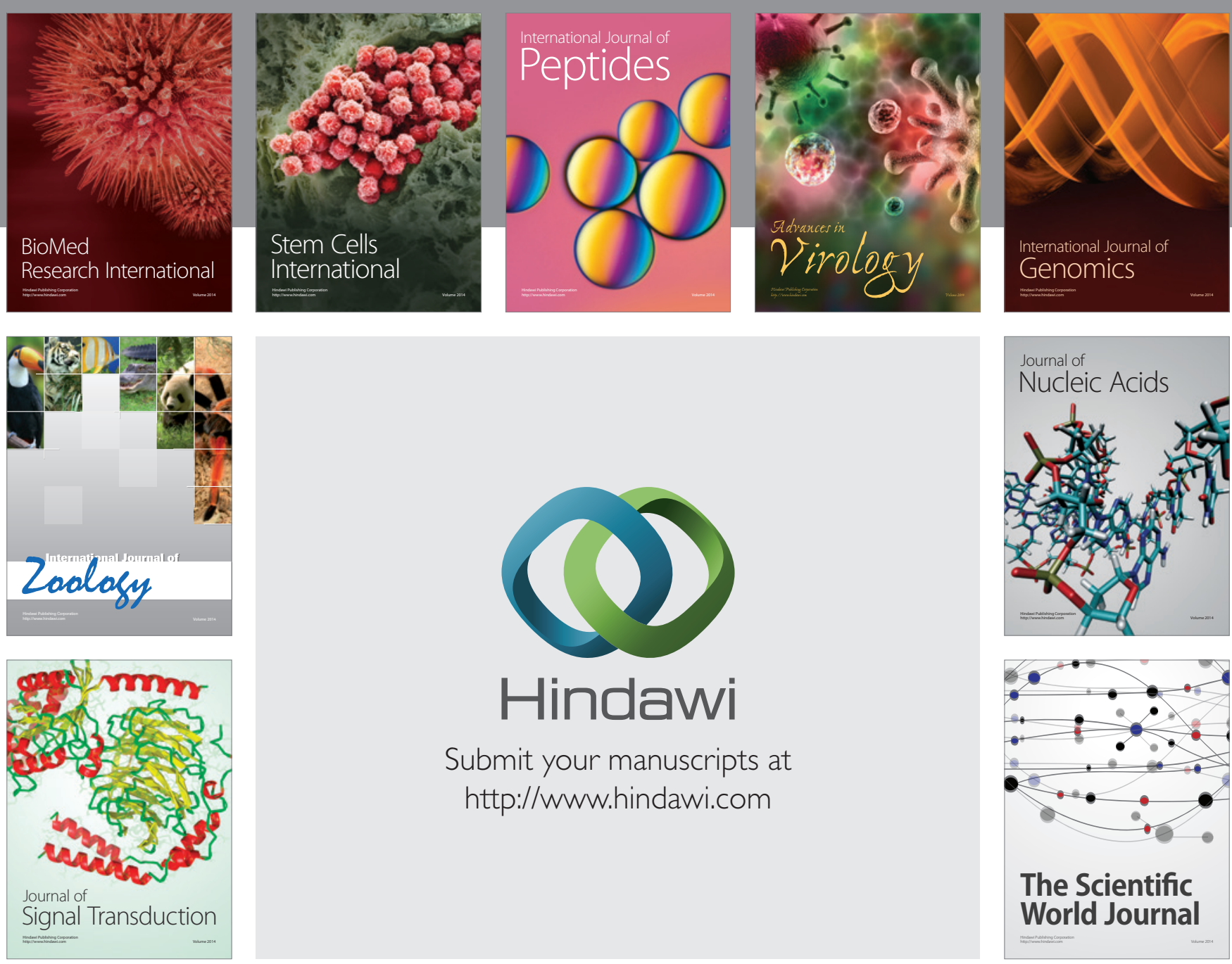

Submit your manuscripts at

http://www.hindawi.com
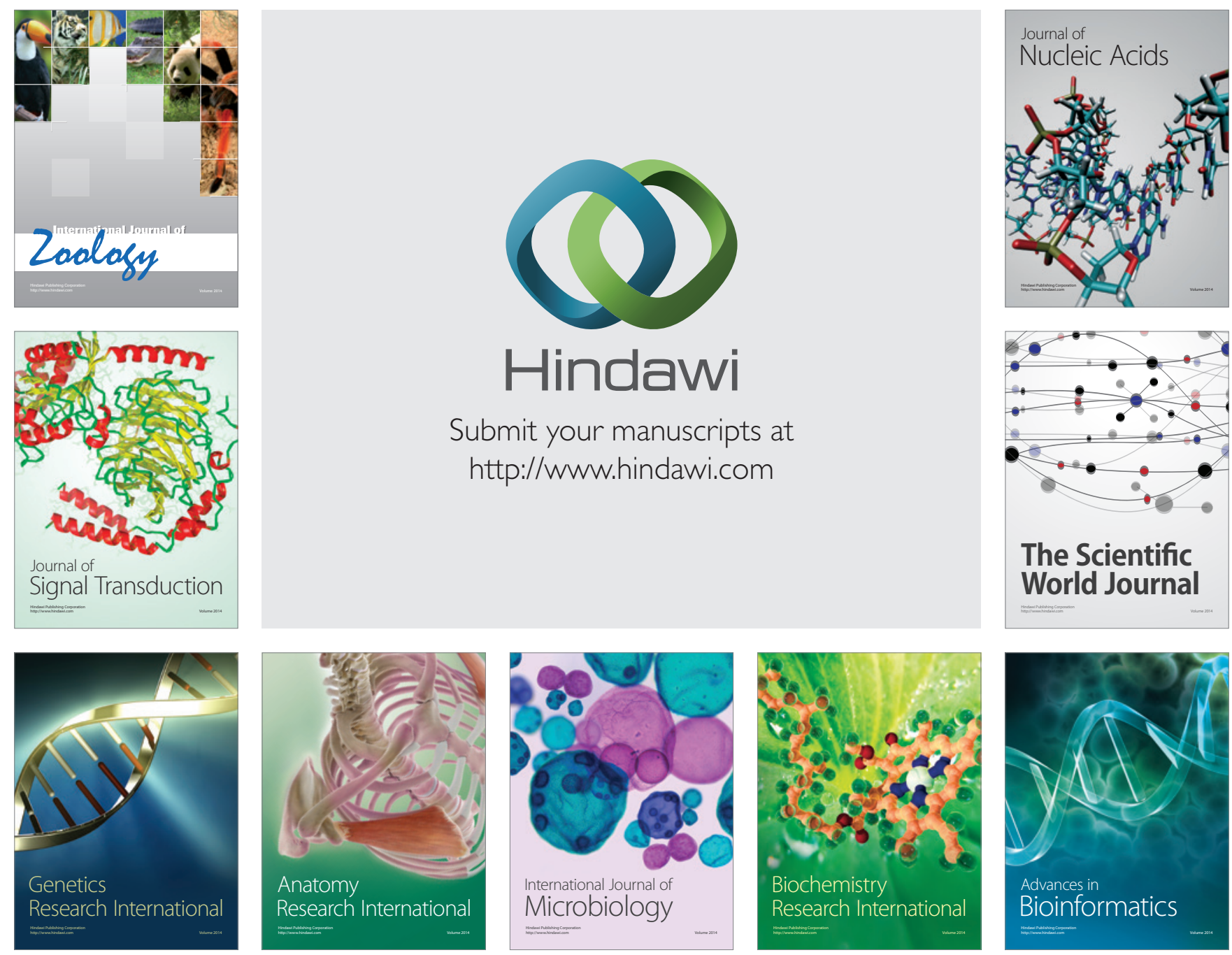

The Scientific World Journal
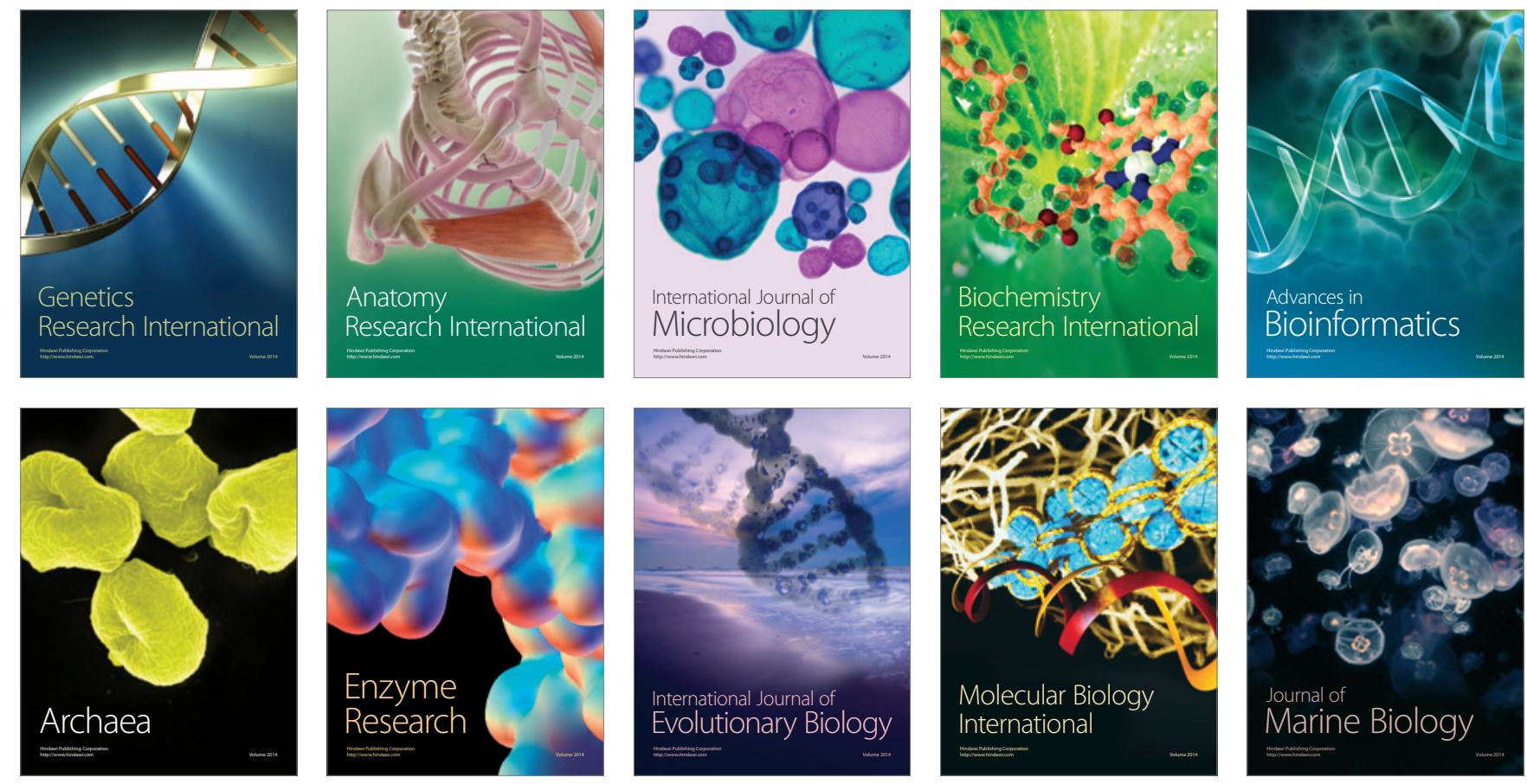